\title{
Caffeic acid prevents hydrogen peroxide-induced oxidative damage in SH-SY5Y cell line through mitigation of oxidative stress and apoptosis
}

\author{
Ayna A \\ Department of Chemistry, Faculty of Arts and Sciences, Bingol University, Bingol, Turkey. \\ aayna@bingol.edu.tr
}

\begin{abstract}
AIM: The aim of this study was to examine the potential ameliorative effects of caffeic acid (CA) on hydrogen peroxide $\left(\mathrm{H}_{2} \mathrm{O}_{2}\right)$-induced neurodegeneration in a human $\mathrm{SH}$-SY5Y cell line, as well as possible mechanisms involved.

METHOD: Cell proliferation was evaluated by WST-1 assay. The apoptotic index was calculated by TUNEL Assay. Antioxidant parameters were studied by measuring reactive oxygen species (ROS), lipid peroxidation (LPO) levels, and catalase (CAT) activity. The mRNA expression levels of apoptotic and anti-apoptotic genes were studied by qRT-PCR

RESULTS: In this study, the pre-treatment with CA significantly suppressed $\mathrm{H}_{2} \mathrm{O}_{2}$-stimulated cell death and apoptosis in SH-SY5Y cell line. The mechanism by which CA pretreatment protected the cells from oxidative injury includes the decrease in ROS and LPO levels, increase in CAT activity, down-regulation of mRNA levels of Bax, cytochrome c, cas-3, cas-8, and p53, and up-regulation of anti-apoptotic Bcl-2 gene. CONCLUSION: These results reveal that CA plays a role in the protection from oxidative injury-triggered apoptosis, which makes CA a likely therapeutic compound for treatment or prevention of neurodegenerative disorders associated with oxidative injury (Fig. 5, Ref. 35). Text in PDF www.elis.sk KEY WORDS: caffeic acid; apoptosis; oxidative stress; cas-3; reactive oxygen species.
\end{abstract}

\section{Introduction}

The frequency of neurodegenerative diseases has been growing owing to the increase in older population. Artificial neuroprotective medicines used for treating the neurodegenerative disorders have been accompanied with some adverse effects. Therefore, more consideration has been attributed to the neuroprotective potential of using natural substances that have fewer adverse effects (1).

Neurodegenerative disorders are associated with DNA mutation in mitochondria and oxidative injury which occurs when reactive oxygen species (ROS) are produced in mitochondria (2-5). Superoxide anion $\left(\mathrm{O}_{2}^{-}\right)$, hydrogen peroxide $\left(\mathrm{H}_{2} \mathrm{O}_{2}\right)$ and hydroxyl radical $\left(\mathrm{OH}^{-}\right)$are among the key ROS. When the levels of ROS overcome the cellular antioxidant protection machinery, oxidative stress occurs, which results in ROS-intermediated destruction of lipids and proteins contributing to neurodegenerative diseases and carcinogenesis (6). For that reason, cells must frequently regulate the amount of ROS and prevent their accumulation. These disorders might be reversed with the aid of antioxidant supplementation with considerable success. Several studies have been carried out to

Department of Chemistry, Faculty of Arts and Sciences, Bingol University, Bingol, Turkey

Address for correspondence: A. Ayna, Department of Chemistry, Faculty of Arts and Sciences, Bingol University, Bingol, Turkey.

Phone: +904262160012-2425, Fax: 00904262160031 develop efficient and non-toxic antioxidants that could be beneficial for the treatment and prevention of neurological disorders (7).

Antioxidants co-operatively perform against free radicals to fight their destructive effects on crucial macro biomolecules and eventually body tissues. Depending on their reaction to the free-radical attack, they have been categorized as first, second, third and even fourth-line defense antioxidants. The role and efficiency of the first-line defense antioxidants, which contain SOD, CAT and GPX, is essential and obligatory in the whole defense scheme of antioxidants. A great deal of studies have been conducted regarding antioxidants, their importance in prohibiting oxidative damage and associated cellular injury, as well as on the vital role of SOD, CAT and GPX (8-11). Caffeic acid (CA) is among the major hydroxycinnamic acid derivatives and represents a potent antioxidant activity (12).

The aim of this study was to examine the potential ameliorative effects of CA on $\mathrm{H}_{2} \mathrm{O}_{2}$-induced neurodegeneration in human neuronal cell line, as well as possible mechanisms involved.

\section{Material and Method}

\section{Cell culture and treatment}

$\mathrm{SH}-\mathrm{SY} 5 \mathrm{Y}$ cells were grown at $37^{\circ}$ in a humidified $5 \% \mathrm{CO}_{2}$, in Dulbecco's modified Eagle's medium complemented with $10 \%$ fatal bovine serum, $1 \%$ penicillin-streptomycin as previously explained (13). 


\section{Experimental groups}

The neuron cells were separated in three groups. In the control group, the cells were grown in complete medium. In $\mathrm{H}_{2} \mathrm{O}_{2}$ group, the cells were grown in the presence of $0.8 \mathrm{mM} \mathrm{H}_{2} \mathrm{O}_{2}$ for $12 \mathrm{~h}$. In $\mathrm{CA}+\mathrm{H}_{2} \mathrm{O}_{2}$ pre-treatment group, the cells were pre-incubated with $\mathrm{CA}(0.1 \mathrm{mM})$ for $3 \mathrm{~h}$, and $0.8 \mathrm{mM} \mathrm{H}_{2} \mathrm{O}_{2}$ was added for $12 \mathrm{~h}$.

\section{Cell proliferation assay}

Cytotoxicity experiments were carried out by water-soluble tetrazolium-1 (WST-1) cell viability assay kit as described in kit procedure (Clontech Laboratories).

\section{Lipid peroxidation (LPO) assay}

In order to evaluate lipid peroxidation level in $\mathrm{H}_{2} \mathrm{O}_{2}$-induced SH-SY5Y cells, a slight modification of previously published procedure was used (14).

\section{Intracellular ROS assay}

Cellular ROS generation was assessed by use of 2'-7'-dichlorodihydrofluorescein diacetate (DCFH-DA) assay kit (Abcam, MA, USA), as previously defined (15).

\section{Catalase (CAT) activity and total antioxidant status (TAS)}

The experiments were carried out following the protocols supplied with the catalase assay kit (Elabscience) and human TAS ELISA kit (SunRed).

\section{TUNEL assay}

The assay was performed following the procedure supplied with the ApopTag kit (Milipore).

\section{QRT-PCR analysis}

The expression levels of the genes studied within this research were investigated by quantitative real-time gene expression assay kit (Jena Bioscience). The expression levels of Bax, Bcl-2, cytochrome $c$, p53, cas-8 cas-3, and glyceraldehyde-3-hosphate dehydrogenase $(G A P D H)$, as a housekeeping gene, were analyzed as previously explained (15).

\section{Caspase-3 staining}

Immuno-histochemical staining experiments were carried out by use of UltraVision LP Large Volume Detection System (Santa Cruz Biotechnology) kit protocol.

\section{Statistics}

All experiments were repeated for at least three times. The statistical analysis and comparable data groups were assessed using GraphPad Prism 5 by one-way ANOVA Newman-Keuls post-hoc test; $\mathrm{p}<0.05$ was considered significant.

\section{Results}

\section{Cell proliferation assay}

The cells were exposed to $25,50,100,200,400$ and $800 \mu \mathrm{MH}_{2} \mathrm{O}_{2}$ for $12 \mathrm{~h}$ ( $24 \mathrm{~h}$ data not given) to decide the concentration and time of $\mathrm{H}_{2} \mathrm{O}_{2}$ exposure needed to produce toxicity on SH-SY5Y cell line. The cell toxicity was evaluated by WST-1 assay. The exposure to $\mathrm{H}_{2} \mathrm{O}_{2}$ for $12 \mathrm{~h}$ reduced the cell proliferation in a dose-dependent and timely manner. As illustrated in Figure $1 \mathrm{~A}, 800 \mu \mathrm{M} \mathrm{H}_{2} \mathrm{O}_{2}$ induced remarkable reductions in cell survival while CA treatment (100 $\mu \mathrm{M}$ ) protected the cells from $\mathrm{H}_{2} \mathrm{O}_{2}$-induced injury (Figs 1A, 1B).

\section{Detection of cellular ROS and LPO level and CAT activity}

The effects of CA pre-treatment on $\mathrm{H}_{2} \mathrm{O}_{2}$-triggered ROS production in SH-SY5Y cells were assessed. The results revealed that $\mathrm{H}_{2} \mathrm{O}_{2}$ exposure led to a remarkable rise in ROS production; however, $100 \mu \mathrm{M}$ CA pre-treatment significantly reduced ROS production (Fig. 2A). To assess whether CA contributed to the protection of neuron cells from $\mathrm{H}_{2} \mathrm{O}_{2}$-induced injury, $\mathrm{LPO}$ assay was performed using $100 \mu \mathrm{M} \mathrm{CA}$. As shown in Figure 2B, the level of LPO in neuron cells from $\mathrm{H}_{2} \mathrm{O}_{2}$ group considerably increased while CA pre-treatment reduced LPO levels, as compared with $\mathrm{SH}-\mathrm{SY} 5 \mathrm{Y}$ cells from $\mathrm{H}_{2} \mathrm{O}_{2}$ group. The CAT activity was significantly decreased in SH-SY5Y cells from the $\mathrm{H}_{2} \mathrm{O}_{2}$ group, as compared to the control group, while CA pre-treatment increased the CAT activity (Fig. 2C).

\section{TUNEL Assay}

The effect of CA on preventing apoptosis triggered by $\mathrm{H}_{2} \mathrm{O}_{2}$ in neuron cells was also evaluated. The results revealed that $\mathrm{H}_{2} \mathrm{O}_{2}$ induced apoptosis by causing breaks in the DNA strand and increasing AI, as determined by TUNEL assay. The pretreatment with CA significantly inhibited the $\mathrm{H}_{2} \mathrm{O}_{2}$-induced apoptosis (Fig. 3).
(A)

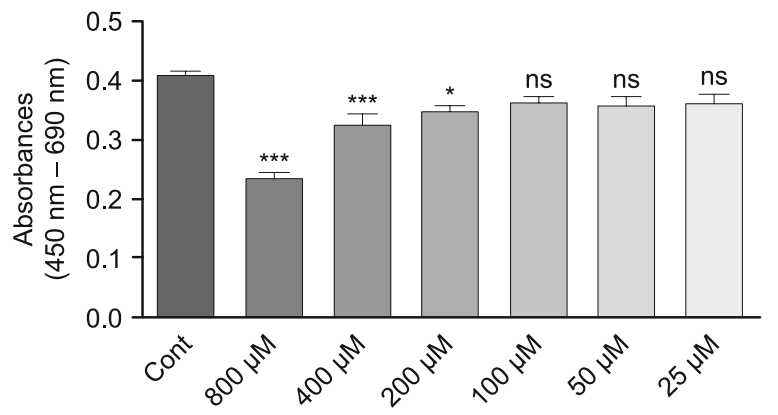

B

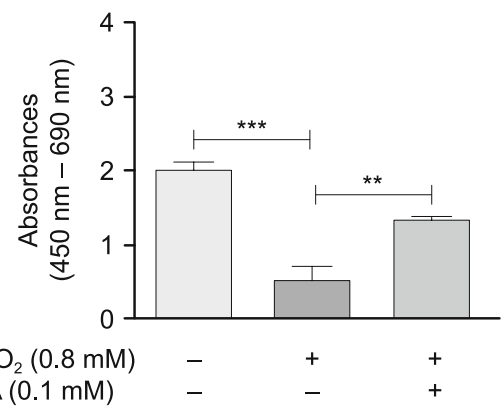

Fig. 1. Effects of $\mathrm{H}_{2} \mathrm{O}_{2}(A)$ and $\mathrm{CA}+\mathrm{H}_{2} \mathrm{O}_{2}$ on neuronal cell proliferation (B). Experimental data are presented as mean $\pm \mathrm{SEM}(\mathrm{n} \geq 3$ ); *** $\mathrm{p}<$ 0.001 points out statistically significant differences between control and other groups; ns: not significant. 

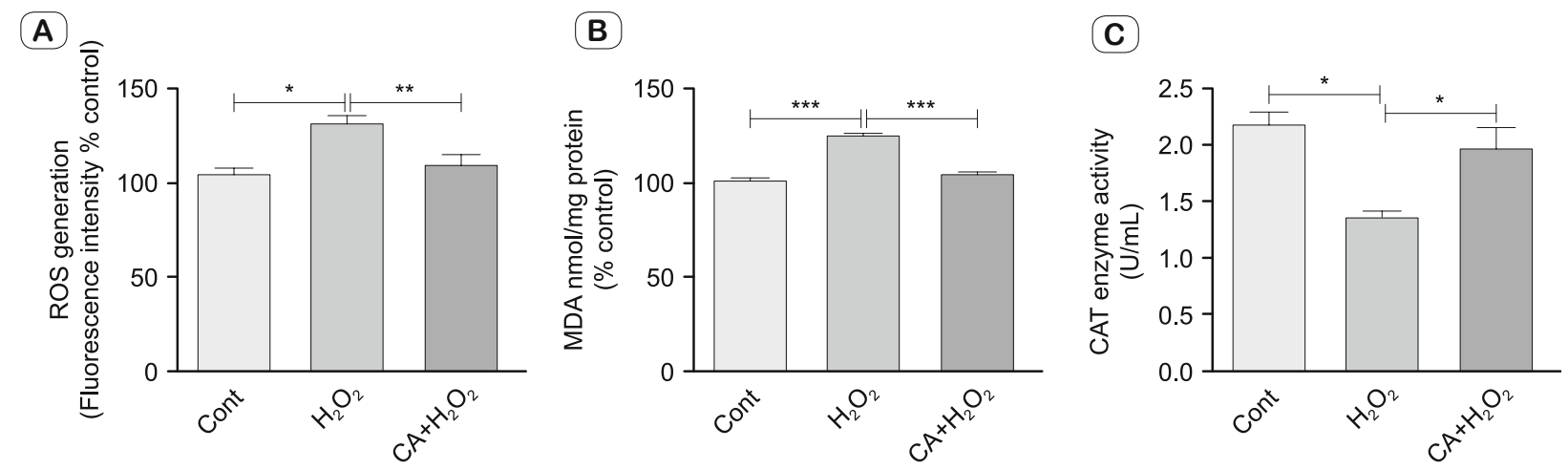

Fig. 2. The effect of CA on $\mathrm{H}_{2} \mathrm{O}_{2}$-induced ROS generation (A), MDA level (B) CAT activity (C) in SH-SY5Y cells. Experimental data are given as mean $\pm \operatorname{SEM}(\mathrm{n} \geq 3) ;{ }^{* * *} \mathrm{p}<0.001,{ }^{* *} \mathrm{p}<0.01,{ }^{*} \mathrm{p}<0.05$ point out statistically significant differences between control and other groups.

\section{Immunohistochemical staining for caspase-3}

To approve whether $\mathrm{H}_{2} \mathrm{O}_{2}$-induced cell toxicity occurred owing to the induction of apoptotic pathway, the activation of caspase-3, an important executioner of apoptosis, was determined. As demonstrated in Figure 4, caspase-3 was considerably activated in SH-SY5Y cells by the exposure to $\mathrm{H}_{2} \mathrm{O}_{2}$ while the pretreatment with CA remarkably reduced the caspase- 3 activation.

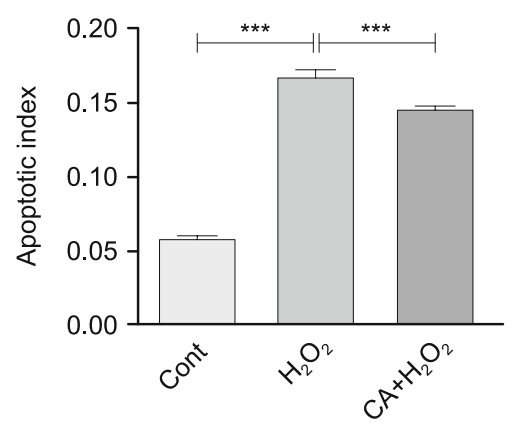

Fig. 3. The effect of $\mathrm{H}_{2} \mathrm{O}_{2}$ and $\mathrm{CA}+\mathrm{H}_{2} \mathrm{O}_{2}$ treatment on apoptosis in SHSY5Y, as compared to the control group. AI was calculated according to the TUNEL assay instructions. Experimental data are given as mean \pm SEM $(n \geq 3) ; * * * \mathbf{p}<0.001$ points out statistically significant differences between control and other groups.

\section{QRT-PCR analysis}

To test whether the expression levels of apoptotic and proapoptotic genes were affected by $\mathrm{H}_{2} \mathrm{O}_{2}$ and $\mathrm{CA}$ treatment, the mRNA levels of Bax, Bcl-2, cytochrome c, p53, cas-8 and cas-3 were measured by qRT-PCR. As illustrated in Figure $5(\mathrm{~A}-\mathrm{F})$, the mRNA levels of Bax, cytochrome c, p53, cas-8 and cas-3 were dramatically upregulated while mRNA levels of anti-apoptotic Bcl-2 were downregulated after $\mathrm{H}_{2} \mathrm{O}_{2}$ exposure. The pretreatment with CA considerably reversed the mRNA levels of these genes.

\section{Discussion}

Neurodegenerative diseases have been characterized by progressive deterioration of the neuronal function as a result of degeneration of synapses and axons eventually leading to the death of neuron cells. More profound comprehension of the mechanisms underlying the altered cellular homeostasis and neurodegeneration is crucial for the development of efficient treatments for the diseases (16). Oxidative stress which happens when the cellular antioxidant defense machinery is overcome by excessive ROS levels might influence the cell viability and survival through activating metabolic cell signaling pathways. Oxidative injury is confirmed as a contribution to the pathology of many neurological disorders
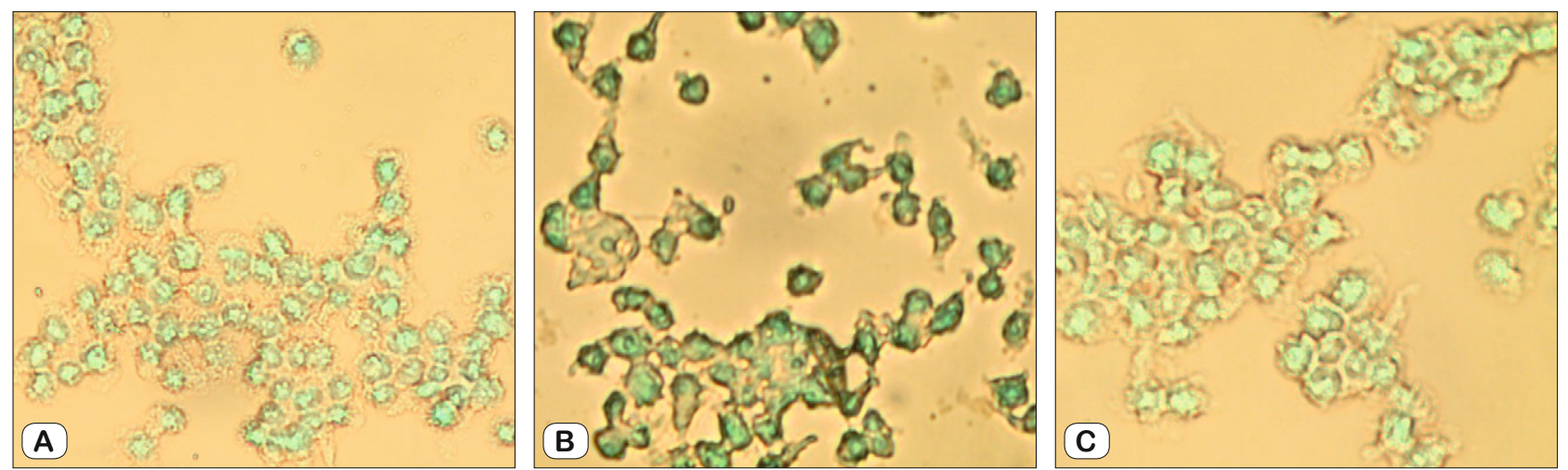

Fig. 4. The effect of $\mathrm{H}_{2} \mathrm{O}_{2}(\mathrm{~B})$ and $\mathrm{CA}+\mathrm{H}_{2} \mathrm{O}_{2}$ treatment $(\mathrm{C})$ on apoptosis related active caspase-3 in $\mathrm{SH}-\mathrm{SY} 5 \mathrm{Y}$ cells, as compared to the control group (A). Caspase-3-expressing cells are characterised by their dark brown colour. 
(A)

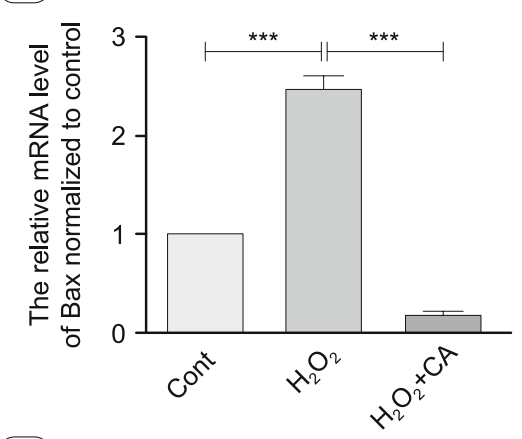

(B)

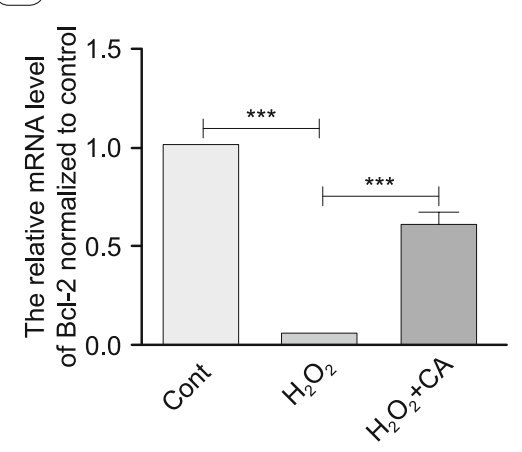

(C)

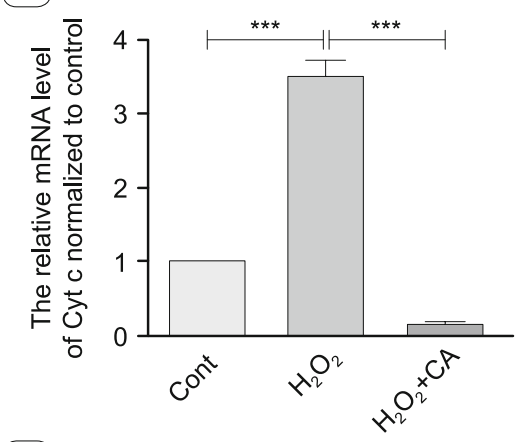

(D)

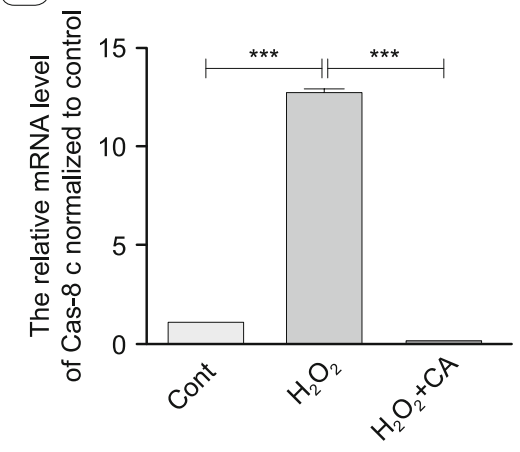

(E)

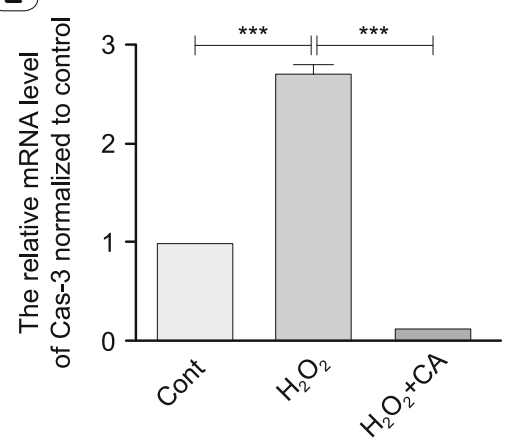

(F)

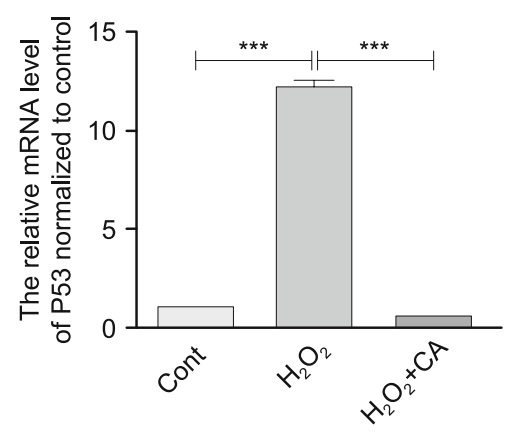

Fig. 5. The effect of $\mathrm{H}_{2} \mathrm{O}_{2}$ and $\mathrm{CA}+\mathrm{H}_{2} \mathrm{O}_{2}$ on the level of apoptosis-related gene expressions in SH-SY5Y cells. The cells were treated as stated in experimental groups. The mRNA levels of pro-apoptotic Bax (A), anti-apoptotic Bcl-2 (B), apoptotic cytochrome c (C), cas-8 (D), cas-3 (E) and $\mathbf{p 5 3}(\mathrm{F})$ were measured by using QRT-PCR analysis. Experimental values are expressed as mean $\pm \operatorname{SEM}(\mathbf{n} \geq 3) ; * * * \mathbf{p}<0.001, * * \mathbf{p}<0.01$, and $* p<0.05$ indicate statistically significant differences between control and other groups; ns: not significant.

(17-19). ROS have been demonstrated to provoke apoptotic cell death in endothelial vascular cells, glial and neuron cells (20-22). $\mathrm{H}_{2} \mathrm{O}_{2}$ has been frequently used to create in vitro models of oxidative injury by triggering excessive generation of ROS through targeting mitochondria, which results in mitochondrial dysfunction (23). A reasonable approach to maintaining cellular redox balance and protecting against oxidative injury lies in eliminating the excessive levels of ROS or inhibiting their production by antioxidants (24, 25). The phenolics that include CA can scavenge the free radicals either directly or via a sequence of coupled reactions with enzymatic antioxidants such as CAT (26-28). Given its reported properties as an antioxidant for oxidative injury, CA can be a motivating candidate to be examined in neurodegenerative models. $\mathrm{H}_{2} \mathrm{O}_{2}$, as an inducer of oxidative damage, revealed antioxidant activity of CA in neuron cells. As predicted, the pretreatment of cells with CA caused resistance to $\mathrm{H}_{2} \mathrm{O}_{2}$ toxicity, as shown by increased cell viability. The effect of CA on intracellular ROS and LPO levels after $\mathrm{H}_{2} \mathrm{O}_{2}$ treatment was also investigated. $\mathrm{H}_{2} \mathrm{O}_{2}$ triggered cellular oxidative injury as measured by ROS level, while the in vitro pre-treatment of neuron cells with CA led to elimination of $\mathrm{H}_{2} \mathrm{O}_{2}$ induced cellular toxicity. In the meantime, the in vitro pretreatment of cells with CA decreased the level of cellular LPO. The catalytic activity of CAT was noticeably reduced in neuron cells from $\mathrm{H}_{2} \mathrm{O}_{2}$ group, as compared to the normal cells, while the CA pretreatment increased the CAT activity. The decrease in oxidative stress associates with the rise in cell viability observed in neuron cells pretreated with $\mathrm{CA}$, which supports the hypothesis that $\mathrm{CA}$ could significantly protect $\mathrm{SH}-\mathrm{SY} 5 \mathrm{Y}$ cells from $\mathrm{H}_{2} \mathrm{O}_{2}$-provoked cell apoptosis.

Several biochemical and physiological studies have been carried out to verify the connection between oxidative damage and apoptosis (29-31). $\mathrm{H}_{2} \mathrm{O}_{2}$ could possibly trigger apoptosis directly, while the presence of antioxidants might inhibit this effect (32). To examine whether $\mathrm{H}_{2} \mathrm{O}_{2}$ caused apoptosis in neurons, the AI was calculated via TUNEL assay. The protective effect of CA pretreatment against neuron apoptosis was studied as well. As shown in Figure 3, $\mathrm{H}_{2} \mathrm{O}_{2}$ treatment considerably increased the apoptotic index, while CA pretreatment remarkably decreased the apoptotic cell death, thus suggesting the protective role of CA in $\mathrm{H}_{2} \mathrm{O}_{2}$-triggered apoptosis in neuron cells.

The apoptotic pathway is accompanied with sequences of biological changes such as in caspase-3 level, a crucial executioner of neuronal apoptosis (33). The tumor suppressor gene $p 53$, the activation of which is reported to trigger apoptosis in various cells including neurons, is an important regulator of cell stress (34). Bax is located in the cytoplasm but translocates to the mitochondrion after cellular death signaling, thus promoting the release of cytochrome c. In the extrinsic pathway, caspase- 8 is shown to have the main role in activating caspase-3 (35). In this research, the treatment with $\mathrm{H}_{2} \mathrm{O}_{2}$ led to the rise in expression of Bax, cytochrome c, cas-8, cas-3, and p53 and to a decrease in mRNA levels of anti-apoptotic $\mathrm{BCl}-2$, while their expression levels were 
decreased by pretreatment with $\mathrm{CA}$, which indicates that CA plays a role in prevention from $\mathrm{H}_{2} \mathrm{O}_{2}$-induced apoptosis in neuron cells.

Overall, the pretreatment with CA noticeably reduced the $\mathrm{H}_{2} \mathrm{O}_{2}$-induced cell toxicity and apoptosis. The machinery, by which CA pretreatment protected SH-SY5Y cells from oxidative damage, covers the reduction in ROS and LPO levels, increase in CAT enzyme activity, downregulation of expression of Bax, cytochrome c, cas-3, cas-8, p53 and upregulation of anti-apoptotic Bcl-2. These results revealed that $\mathrm{CA}$ has a role in protection from oxidative injury-triggered apoptotic pathway, which makes CA a possible therapeutic compound in the treatment of or prevention from neurodegenerative disorders associated with oxidative injury.

\section{Reference}

1. Liu XG, Sun YQ, Bian J, Han T, Yue DD, Li DQ, Gao PY. Neuroprotective effects of triterpenoid saponins from Medicago sativa L. against $\mathrm{H} 2 \mathrm{O} 2-$ induced oxidative stress in SH-SY5Y cells. Bioorg Chem 2019; 83: 468-476.

2. Droge W. Free radicals in the physiological control of cell function. Physiol Rev 2002; 82 (1): 47-95.

3. González-Sarrías A, Núñez-Sánchez MA, Tomás-Barberán FA, Espín JC. Neuroprotective effects of bioavailable polyphenol-derived metabolites against oxidative stress-induced cytotoxicity in human neuroblastoma SHSY5Y cells. J Agric Food Chem 2016; 65 (4): 752-758.

4. Halliwell B. Oxidative stress and neurodegeneration: where are we now? J Neurochem 2006; 97 (6): 1634-1658.

5. Dringen R, Pawlowski PG, Hirrlinger J. Peroxide detoxification by brain cells. J. Neurosci Res 2005; 79 (1-2): 157-165.

6. Ray PD, Huang BW, Tsuji Y. Reactive oxygen species (ROS) homeostasis and redox regulation in cellular signaling. Cell Signal 2012; 24 (5): 981-990.

7. Karpińska A, Gromadzka G. Oxidative stress and natural antioxidant mechanisms: the role in neurodegeneration. From molecular mechanisms to therapeutic strategies. Postepy Hig Med Dosw 2013; 67: 43-53.

8. Aebi H. Catalase in vitro. In Methods in enzymology. Academic Press 1984; 105: 121-126.

9. Abreu IA, Cabelli DE. Superoxide dismutases - a review of the metalassociated mechanistic variations. Biochim et Biophys Acta (BBA)-Proteins and Proteomics 2010; 1804(2): 263-274.

10. Haida Z, \& Hakiman MA. comprehensive review on the determination of enzymatic assay and nonenzymatic antioxidant activities. Food Sci Nutr 2019; 7 (5): 1555-1563.

11. Chen JH, Ho CT. Antioxidant activities of caffeic acid and its related hydroxycinnamic acid compounds. J Agric Food Chem 1997; 45 (7): 2374-2378.

12. Gülçin İ. Antioxidant activity of caffeic acid (3, 4-dihydroxycinnamicacid). Toxicol 2006; 217 (2-3): 213-220.

13. Darendelioglu E, Aykutoglu G, Tartik M, Baydas G. Turkish propolis protects human endothelial cells in vitro from homocysteine-induced apoptosis. Acta Histochem 2016; 118 (4): 369-376.

14. Dawn-Linsley M, Ekinci FJ, Ortiz D, Rogers E, Shea TB. Monitoring thiobarbituric acid-reactive substances (TBARs) as an assay for oxidative damage in neuronal cultures and central nervous system. J Neurosci Methods 2005; 141 (2): 219-222.

15. Tartik M, Darendelioglu E, Aykutoglu G, Baydas G. Turkish propolis supresses MCF-7 cell death induced by homocysteine. Biomed Pharmacother 2016; 82: 704-712.

16. Andreone BJ, Larhammar M, Lewcock JW. Cell death and neurodegeneration. Cold Spring Harb Perspect Biol 2020; 12(2): a036434.
17. Singh A, Kukreti R, Saso L, Kukreti S. Oxidative stress: A key modulator in neurodegenerative diseases. Molecules 2019; 24 (8): 1583.

18. Lin CJ, Chen TH, Yang LY, Shih CM. Resveratrol protects astrocytes against traumatic brain injury through inhibiting apoptotic and autophagic cell death. Cell Death Dis 2014; 5 (3): e1147.

19. Wang M, Li YJ, Ding Y, Zhang HN, Sun T, Zhang K, Wu YM. Silibinin prevents autophagic cell death upon oxidative stress in cortical neurons and cerebral ischemia-reperfusion injury. Mol Neurobiol 2016; 53 (2): 932-943.

20. Piras S, Furfaro AL, Domenicotti C, Traverso N, Marinari UM, Pronzato MA, Nitti, M. RAGE expression and ROS generation in neurons: differentiation versus damage. Oxid Med Cell Longev 2016; 2016: 1-9.

21. Kwon IS, Kim J, Rhee DK, Kim BO, Pyo S. Pneumolysin induces cellular senescence by increasing ROS production and activation of MAPK/ NF-kB signal pathway in glial cells. Toxicon 2017; 129: 100-112.

22. Mongiardi MP, Radice G, Piras M, Stagni V, Pacioni S, Re A, Barilà D. Axitinib exposure triggers endothelial cells senescence through ROS accumulation and ATM activation. Oncogene 2019; 1

23. Rigoulet M, Yoboue ED, Devin A. Mitochondrial ROS generation and its regulation: mechanisms involved in $\mathrm{H} 2 \mathrm{O} 2$ signaling. Antioxid Redox Sig 2011; 14 (3): 459-468.

24. Poljsak B, Šuput D, Milisav I. Achieving the balance between ROS and antioxidants: when to use the synthetic antioxidants. Oxid Med Cell Longev 2013.

25. Shahidi F, Janitha PK, Wanasundara PD. Phenolic antioxidants. Crit Rev Food Sci Nutr 1992; 32 (1): 67-103.

26. Meyer AS, Donovan JL, Pearson DA, Waterhouse AL, Frankel EN. Fruit hydroxycinnamic acids inhibit human low-density lipoprotein oxidation in vitro. JAgric Food Chem 1998; 46 (5): 1783-1787.

27. Cartron E, Carbonneau MA, Fouret G, Descomps B, Léger CL. Specific antioxidant activity of caffeoyl derivatives and other natural phenolic compounds: LDL protection against oxidation and decrease in the proinflammatory lysophosphatidylcholine production. J Nat Prod 2001; 64 (4): 480-486.

28. Kikuzaki H, Hisamoto M, Hirose K, Akiyama K, Taniguchi H. Antioxidant properties of ferulic acid and its related compounds. J Agric Food Chem 2002; 50 (7): 2161-2168.

29. Halliwell B, Zhao K, Whiteman M. The gastrointestinal tract: a major site of antioxidant action? Free Radic Res 2000; 33 (6): 819-830.

30. Kujoth GC, Hiona A, Pugh TD, Someya S, Panzer K, Wohlgemuth SE, Morrow JD. Mitochondrial DNA mutations, oxidative stress, and apoptosis in mammalian aging. Science, 2005; 309 (5733): 481-484.

31. Poh Loh K, Hong Huang S, De Silva R, Tan H, Benny K, Zhun Zhu Y. Oxidative stress: apoptosis in neuronal injury. Curr Alzheimer Res 2006; 3 (4): 327-337.

32. Suematsu N, Hosoda M, Fujimori K. Protective effects of quercetin against hydrogen peroxide-induced apoptosis in human neuronal SH-SY5Y cells. Neurosci Lett 2011; 504 (3): 223-227.

33. Hartmann A, Hunot S, Michel PP, Muriel MP, Vyas S, Faucheux BA, Evan GI. Caspase-3: a vulnerability factor and final effector in apoptotic death of dopaminergic neurons in Parkinson's disease. Proc Natl Acad Sci USA 2000; 97 (6): 2875-2880.

34. Culmsee C, Mattson MP. p53 in neuronal apoptosis. Biochem Biophys Res Commun 2005; 331 (3): 761-777.

35. Stennicke HR, Jürgensmeier JM, Shin H, Deveraux Q, Wolf BB, Yang $\mathbf{X}$, Green DR. Pro-caspase-3 is a major physiologic target of caspase-8. J Biol Chem 1998; 273(42): 27084-27090. 